\section{Suppression by Diets Rich in Fish Oil of Very Low Density Lipoprotein Production in Man}

Paul J. Nestel, William E. Connor, Michael F. Reardon, Sonja Connor, Sue Wong, and Ray Boston

Baker Medical Research Institute, Prahran, Victoria, Australia bstract. The highly polyunsaturated fatty acids in fish oils lower the plasma triglyceride concentration. We have studied the effect of a diet rich in fish oil on the rate of production of the triglyceride-transporting very low density lipoprotein (VLDL). Seven subjects, five normal and two with hypertriglyceridemia received up to $30 \%$ of daily energy needs from a fish oil preparation that was rich in eicosapentaenoic acid and docosahexaenoic acid, $\omega-3$ fatty acids with five and six double bonds, respectively.

Compared with a diet similarly enriched with safflower oil (in which the predominant fatty acid is the $\omega-6$ linoleic acid, with two double bonds), the fish oil diet lowered VLDL lipids and $B$ apoprotein concentrations profoundly. High density lipoprotein lipids and $\mathrm{A}_{1}$ apoprotein were also lowered, but the effect on low density lipoprotein (LDL) concentration was inconsistent.

The daily production or flux of VLDL apoprotein B, calculated from reinjected autologous ${ }^{125}$ I-labeled lipoprotein, was substantially less in six subjects studied after 3 wk of fish oil, compared with after safflower oil. This effect on flux was more consistent than that on the irreversible fractional removal rate, which was increased in the four normolipidemic but inconsistent in the hy-

This work was presented in part at the Annual Meeting of the American Heart Association, Anaheim, California, 1983.

Drs. W. E. and S. Connor are with the Department of Medicine, Oregon Health Sciences Laboratory, Portland, Oregon. Dr. Boston is with the Department of Agriculture, LaTrobe University, Bundoora, Victoria, Australia. Dr. W. E. Connor was the Warren MacDonald International Fellow of the National Heart Foundation of Australia.

Please address all correspondence to Dr. Nestel, Baker Medical Research Institute, Commercial Rd., Melbourne 3181, Australia.

Received for publication 3 June 1983 and in revised form 28 February 1984.

J. Clin. Invest.

(c) The American Society for Clinical Investigation, Inc.

0021-9738/84/07/0082/08 \$1.00

Volume 74, July 1984, 82-89 pertriglyceridemic subjects. This suggests that fish oil reduced primarily the production of VLDL.

The daily production of VLDL triglyceride, calculated from the kinetics of the triglyceride specific radioactivitytime curves after $\left[{ }^{3} \mathrm{H}\right]$ glycerol was injected, also showed very substantial reductions in five subjects studied.

The marked suppression in VLDL apoprotein B and VLDL triglyceride formation was found not to be due to diminished plasma total free fatty acid or plasma eicosapentaenoic flux, calculated during constant infusions of $\left[{ }^{14} \mathrm{C}\right]$ eicosapentaenoic acid and $\left[{ }^{3} \mathrm{H}\right]$ oleic acid in four subjects.

In two subjects there was presumptive evidence for substantial independent influx of LDL during the fish oil diet, based on the precursor-product relationship between the intermediate density lipoprotein and LDL apoprotein B specific radioactivity-time curves.

\section{Introduction}

The fatty acids of fish oils are quite different from those of most land animals and vegetable oils. Marine fatty acids, especially from cold waters, are rich in polyunsaturated fatty acids (PUFA) ${ }^{1}$ of the $\omega-3$ series (the first double bond at the 3-carbon position from the methyl end) and contain up to six double bonds (1). By contrast, vegetable oils tend to be rich in linoleic acid ( $\omega-6$, two double bonds). For example, cod oil contains $51 \%$ of its fatty acid as $\omega-3$, whereas corn oil contains $57 \%$ as $\omega-6$.

Recent studies of men eating marine PUFA have shown a striking reduction in their plasma lipids, especially in triglyceride within very low density lipoproteins (VLDL) (2-4). Rapid and substantial lowering of plasma triglyceride is achieved in patients with severe hypertriglyceridemia.

The mechanism for this profound lipid-lowering effect is unknown, and though the effect is greater with marine than

1. Abbreviations used in this paper: FCR, irreversible fractional removal rate; FFA, free fatty acid; HDL, IDL, LDL, and VLDL, high, intermediate, low, and very low density lipoproteins; PUFA, polyunsaturated fatty acids; Sf, Svedberg floatation unit. 
with vegetable oil PUFA, it is possible that the modes of action are similar. Linoleic acid-rich oils have been reported to reduce the production and increase the clearance of VLDL in man (57). Isolated rat hepatocytes (8) and perfused rat livers (9) esterify relatively less linoleic acid than unsaturated fatty acids of similar carbon chain length; this might reflect a diversion of fatty acid metabolism from triglyceride formation to other pathways, such as oxidation and ketogenesis.

This paper presents measurements of VLDL apoprotein B and triglyceride transport in subjects eating diets enriched with either safflower oil or marine oil. The experiments were designed to determine the major mechanism responsible for the fish-oil induced lowering of plasma triglyceride in man.

\section{Methods}

Lipoprotein transport studies were carried out in seven subjects, five healthy young men who volunteered and two hyperlipidemic patients (Table I). Four others took part in studies of free fatty acid (FFA) transport. The normolipidemic subjects were studied on the metabolic ward. One hyperlipidemic patient was an inpatient (subject 5), the other a closely supervised outpatient (subject 6); they were provided with the oil supplements and kept diaries of food intake. The lipid-lowering drug, clofibrate, was stopped $5 \mathrm{wk}$ before the studies began on subject 5 .

In the lipoprotein transport studies (subjects 1-7) the dietary comparison was between fish oil and safflower oil. Each diet was from 2 to $3.5 \mathrm{wk}$ long, enough time to induce new steady plasma triglyceride and cholesterol concentrations, based on values during the last $5 \mathrm{~d}$ of each study. Dietary details are shown in Table II. Protein was derived mainly from skim milk, egg white, and vegetables. Carbohydrates were predominantly from vegetable and cereal sources. The fat content of the diet provided $\sim 30 \%$ energy. Whereas in subjects $1,2,5$, and 7 most of this derived from either fish oil or safflower oil, less fish oil was given to subjects 3, 4, and 6 . Energy intake to maintain body weight was calculated beforehand and minor adjustments were made later if needed. The fish oil was given as the second diet in all subjects. The fish oil (trade name MaxEPA) was obtained from British Cod Liver Oils Ltd. (Hull, England). The fatty acid composition is shown in Table IV. The oil contained no vitamin D, less than $100 \mathrm{IU}$ vitamin $\mathrm{A} / \mathrm{g}$, and 3.64 $\mathrm{mg}$ cholesterol/g. $\alpha$-Tocopherol was added as antioxidant. Informed consent was obtained.

Lipoprotein apoprotein B kinetics. Plasma was obtained from subjects 1-6 fasted overnight and the lipoproteins were isolated in a $50 \mathrm{Ti}$ rotor of an ultracentrifuge (L565; Beckman Instruments, Inc., Fullerton, CA). An initial centrifugation at $17,000 \mathrm{rpm}$ for $30 \mathrm{~min}$ through $0.15 \mathrm{M}$ $\mathrm{NaCl}$ layered over the plasma was carried out to remove possible chylomicrons. The VLDL (Svedberg flotation unit [Sf], 20-400) for reinjection into subjects $1-6$ were obtained by centrifuging plasma at 40,000 $\mathrm{rpm}$ for $16 \mathrm{~h} \mathrm{(10)}$ and washed by centrifuging once more at $40,000 \mathrm{rpm}$ for $16 \mathrm{~h}$. The lipoprotein protein was then radioiodinated with ${ }^{125} \mathrm{I}$ (less than one atom iodine per mole of protein) (11);36-60\% of the labeled protein was in apoprotein B, as judged by precipitation of the protein with isopropanol, and less than $11 \%$ of total label was in lipid (12). The lipoprotein was sterilized, tested to be pyrogen-free, and reinjected (8$65 \mu \mathrm{Ci}$ total radioactivity). Potassium iodide, $180 \mathrm{mg}$ daily, was given before and after the injection to reduce thyroidal uptake of radioiodine.

Samples of blood were taken between $10 \mathrm{~min}$ and $48 \mathrm{~h}$ after reinjection for measurement of apoprotein $\mathrm{B}$ specific radioactivity in reisolated lipoproteins; VLDL (Sf, 20-400), intermediate density lipoprotein (IDL) (Sf, 12-20), and low density lipoprotein (LDL) (Sf, 0-12) were obtained by sequential ultracentrifugation in the $50 \mathrm{Ti}$ anglehead rotor. Apoprotein B was precipitated with isopropanol and assayed for radioactivity and mass (13). The specific radioactivity-time curves of VLDL apoprotein B when plotted semilogarithmically were resolved into two exponentials in all studies except in subject 5 during the first (safflower oil) study. The latter specific radioactivity-time curve appeared monoexponential over $48 \mathrm{~h}$.

Table I. Clinical Details on Test Subjects

\begin{tabular}{|c|c|c|c|c|c|c|c|}
\hline \multirow[b]{2}{*}{ Subject } & \multirow[b]{2}{*}{ Age } & \multirow[b]{2}{*}{ Weight } & \multirow[b]{2}{*}{ Height } & \multirow[b]{2}{*}{ Clinical notes } & \multicolumn{2}{|c|}{ Plasma lipids* } & \multirow[b]{2}{*}{ Experimental study } \\
\hline & & & & & Cholesterol & Triglyceride & \\
\hline & $y r$ & $k g$ & $\mathrm{~cm}$ & & $m g / d l$ & $m g / d l$ & \\
\hline 1 & 26 & 51 & 160 & Normal & 171 & 115 & Apo B kinetics \\
\hline 2 & 39 & 74 & 172 & Normal & 190 & 115 & Apo $B$ and TG kinetics \\
\hline 3 & 26 & 70 & 173 & Normal & 211 & 56 & Apo B kinetics \\
\hline 4 & 26 & 77 & 167 & Normal & 174 & 94 & Apo $B$ and TG kinetics \\
\hline 5 & 48 & 80 & 178 & Hypertriglyceridemia & 325 & 852 & Apo B and TG kinetics \\
\hline 6 & 44 & 105 & 178 & $\begin{array}{l}\text { Combined } \\
\text { hyperlipoproteinemia }\end{array}$ & 345 & 542 & Apo $B$ and TG kinetics \\
\hline 7 & 22 & 74 & 181 & Normal & 175 & 61 & TG kinetics \\
\hline 8 & 29 & 77 & 182 & Normal & 161 & 42 & FFA kinetics \\
\hline 9 & 23 & 70 & 173 & Normal & 166 & 64 & FFA kinetics \\
\hline 10 & 27 & 66 & 179 & Normal & 121 & 77 & FFA kinetics \\
\hline 11 & 25 & 65 & 174 & Normal & 201 & 80 & FFA kinetics \\
\hline
\end{tabular}

* Values were obtained 1-2 wk before admission to the hospital and are representative of habitual plasma lipid concentrations. $¥$ Apolipoprotein (Apo) B and triglyceride (TG) kinetics in VLDL. 
Table II. Composition and Duration of Diets

\begin{tabular}{|c|c|c|c|c|c|c|c|c|c|c|c|c|c|}
\hline \multirow[b]{2}{*}{$\begin{array}{l}\text { Sub- } \\
\text { ject }\end{array}$} & \multirow[b]{2}{*}{$\begin{array}{l}\text { Duration } \\
\text { of diet }\end{array}$} & \multicolumn{6}{|l|}{ Study I } & \multicolumn{6}{|l|}{ Study II } \\
\hline & & Energy & Protein & $\begin{array}{l}\text { Carbo- } \\
\text { hydrate }\end{array}$ & Fat & $\begin{array}{l}\text { Choles- } \\
\text { terol* }\end{array}$ & $\mathbf{P} / \mathbf{S} \ddagger$ & Energy & Protein & $\begin{array}{l}\text { Carbo- } \\
\text { hydrate }\end{array}$ & Fat & $\begin{array}{l}\text { Choles- } \\
\text { terol* }\end{array}$ & $\mathbf{P} / \mathbf{S} \ddagger$ \\
\hline & $w k$ & kcal & $\begin{array}{l}\% \\
\text { energy }\end{array}$ & $\begin{array}{l}\% \\
\text { energy }\end{array}$ & $\begin{array}{l}\% \\
\text { energy }\end{array}$ & $m g$ & & $k c a l$ & $\begin{array}{l}\% \\
\text { energy }\end{array}$ & $\begin{array}{l}\% \\
\text { energy }\end{array}$ & $\begin{array}{l}\% \\
\text { energy }\end{array}$ & $m g$ & \\
\hline 1 & 3.5 & 2,693 & 15 & 55 & $30(82 \%$ SO $) \S$ & 212 & $4.63(63 \% \omega-6)^{\|}$ & 2,707 & 15 & 55 & 30 (60\% FO) & 210 & $2.2(20 \% \omega-3)^{\|}$ \\
\hline 2 & 3.5 & 2,799 & 15 & 55 & $30(80 \%$ SO) & 408 & $4.50(63 \% \omega-6)$ & 2,793 & 15 & 55 & 30 (89\% FO) & 402 & $1.16(29 \% \omega-3)$ \\
\hline 3 & 3 & 2,796 & 15 & 55 & 30 (79\% SO) & 210 & $4.40(62 \% \omega-6)$ & 2,796 & 15 & 56 & 29 (59\% FO) & 208 & $2.3(19 \% \omega-3)$ \\
\hline 4 & 3 & 2,796 & 15 & 55 & $30(79 \%$ SO) & 215 & $4.40(62 \% \omega-6)$ & 2,796 & 15 & 56 & 29 (59\% FO) & 208 & $2.3(19 \% \omega-3)$ \\
\hline 5 & 3 & 2,708 & 16 & 54 & 30 (64\% SO) & 390 & $3.11(55 \% \omega-6)$ & 2,680 & 15 & 55 & 30 (72\% FO) & 386 & $0.95(23 \% \omega-3)$ \\
\hline 6 & 2 & 2,835 & 15 & 55 & 30 (75\% SO) & 395 & $4.10(59 \% \omega-6)$ & 2,835 & 15 & 55 & 30 (72\% FO) & 380 & $0.95(19 \% \omega-3)$ \\
\hline 7 & 3 & 2,796 & 15 & 55 & $30(79 \%$ SO $)$ & 215 & $4.40(62 \% \omega-6)$ & 2,796 & 15 & 56 & $29(59 \%$ FO) & 208 & $2.3(19 \% \omega-3)$ \\
\hline
\end{tabular}

* Cholesterol content of fish oil was $3.6 \mathrm{mg} / \mathrm{g}$ and was balanced during alternate diet by egg yolk. $¥$ Ratio of polyunsaturated (P) ( $\omega-3+\omega-6)$ to saturated (S) fatty acids. § Percent of total fat by weight as safflower oil (SO) or fish oil (FO). The oil was given in three equal amounts each day. "Percent of total fat by weight as $\omega-6$ or $\omega-3$ fatty acid.

The transport of apoprotein B in VLDL was calculated by conventional one- and two-pool analysis. For the single monoexponential curve, the irreversible fractional removal rate was calculated as $0.693 / t_{1 / 2}(14)$. For the remaining curves, the irreversible fractional removal rate was calculated as $(\alpha \cdot \beta) / K_{\mathrm{BA}}$, where $\alpha$ and $\beta$ are the exponentials describing loss of radioactivity from the rapid and slowly exchanging compartments $\mathrm{A}$ and $\mathrm{B}$, respectively, and $K_{\mathrm{BA}}$ is the fractional rate of transfer of material from pool B to A. $K_{\mathrm{BA}}=\alpha+\beta+K_{\mathrm{AA}}$. ( $K_{\mathrm{AA}}$ is the fractional removal rate from pool $A$ both to pool $B$ and irreversibly from the system. $K_{\mathrm{AA}}=-\left(\alpha \cdot \mathrm{C}_{\mathrm{A}}+\beta \cdot \mathrm{C}_{\mathrm{B}}\right) /\left(\mathrm{C}_{\mathrm{A}}+\mathrm{C}_{\mathrm{B}}\right)$, where $\mathrm{C}_{\mathrm{A}}$ and $\mathrm{C}_{\mathrm{B}}$ are the respective zero-time intercepts for $\alpha$ and $\beta$.) (15)

Transport was calculated by multiplying the irreversible fractional removal rate by the pool size, measured as the amount of VLDL apoprotein $\mathrm{B}$ in plasma (plasma $=4.5 \%$ body mass). The mass of protein in pool A, the rapidly exchanging compartment, was calculated separately from the dilution of the injected radioactivity as radioactivity injected/ $\left(C_{A}+C_{B}\right)($ reference 15). Apoprotein B was assayed as the isopropanol precipitable protein by the Lowry method (13) using bovine albumin as the standard, without correcting for chromogenicity differences.

$V L D L$ triglyceride kinetics. During the final $2 \mathrm{~d}$, when the triglyceride and apoprotein B kinetics were carried out, only carbohydrate $(90 \%$ of energy) and protein were eaten. This ensured that only small variations in VLDL triglyceride concentration occurred (mostly $\pm 5 \%$ of the average in the first six samples taken during the morning after the radioglycerol injection). This value was taken to represent the VLDL triglyceride concentration due to each treatment. The total energy consumed daily during the kinetic studies was $\sim 85 \%$ of that eaten previously.

$200 \mu \mathrm{Ci}$ of $\left[2{ }^{3} \mathrm{H}\right] \mathrm{glycerol}$ (The Radiochemical Centre Ltd., Amersham, England) was injected together with ${ }^{125}$ I-VLDL (except in subject 7) on the morning after the subject had fasted overnight. Samples of blood were initially taken every hour for $5 \mathrm{~h}$ and then less frequently, for a total of $48 \mathrm{~h}$. Lunch, dinner, and supper (containing minimal fat) were then eaten at the usual times.

Lipoproteins (VLDL) were isolated from plasma by ultracentrifugation as described. Aliquots of VLDL were extracted with $30 \mathrm{vol}$ isopropanol, and phospholipids were removed by adsorption onto alumina. A portion of the extract was used to determine triglyceride concentration by the Neri and Frings (16) method. The remainder of the extract was evaporated and dissolved into scintillation fluid (Instagel; Packard Instrument Co., Melbourne) for analysis of radioactivity.

The specific activity-time curves were analyzed as described by Zech et al. (17) through linear first-order compartmental modeling. The incorporation of glycerol into triglyceride assumes two hepatic pathways, one being faster than the other, followed by a series of delipidation steps of plasma VLDL. Compartmental modeling was essential for these studies to take into account the incorporation of glycerol into triglyceride in the liver and the secretion and delipidation of VLDL. The apoprotein B data could be analyzed more simply, since they represented only the removal, through delipidation, of VLDL.

$F F A$ flux. In four additional normotriglyceridemic healthy subjects, we compared the transport of eicosapentaenoic acid with that of oleic acid, the major plasma FFA. This was carried out after $7 \mathrm{~d}$ of a MaxEPArich diet ( $20 \%$ of energy), as described above. This was enough time to raise plasma eicosapentaenoic acid levels to concentrations that could be measured accurately and to lower plasma triglyceride and VLDL concentrations substantially in normal subjects. Flux rates were determined during constant infusions of the radiolabeled FFA.

$\left[9-{ }^{3} \mathrm{H}\right]$ oleic acid and $\left[{ }^{14} \mathrm{C}\right]$ eicosapentaenoic acids were purchased from The Radiochemical Centre Ltd. The purity of both fatty acids was established by co-chromatography with pure unlabeled compounds by thin layer silicic acid chromatography and found to be $>95 \%$ radiochemically pure. Each fatty acid was complexed as its sodium soap to human serum albumin, sterilized by filtration (Millipore Corp., Bedford, MA), and checked for pyrogenicity. The fatty acid-albumin solutions were then infused together at a constant rate, following a bolus injection of about $20 \%$ of the total dose. Approximately $60 \mu \mathrm{Ci}$ of ${ }^{3} \mathrm{H}$ and 10 $\mu \mathrm{Ci}$ of ${ }^{14} \mathrm{C}$ were infused over $3 \mathrm{~h}$ into a forearm vein. Blood was collected from an indwelling nonheparinized catheter placed in the opposite arm, at intervals of $30 \mathrm{~min}$, into chilled heparinized tubes.

Plasma lipids were extracted into isopropanol, heptane, $\mathrm{H}_{2} \mathrm{SO}_{4}$ solution, and aliquots were then separated by thin-layer chromatography to yield FFA for gas chromatographic analysis. Additional aliquots of lipid were subjected to saponification with ethanolic $\mathrm{NaOH}$, and the nonsaponifiable lipids were removed with petroleum ether. The saponified 
lipids containing FFA and phospholipid were hydrolyzed with $\mathrm{HCl}$ and extracted in petroleum ether. Radioactivity was assayed in the total saponifiable fraction by dual isotope counting with appropriate quench corrections. Further separation of the saponifiable lipids by thin-layer chromatography showed that $>90 \%$ of the radioactivity was present in FFA. Recovery of lipid radioactivity through the saponification procedures was $\sim 95 \%$, and no corrections for losses or for contamination by radioactivity in phospholipids have been made in calculating the FFA radioactivity.

Total plasma FFA concentration was measured by the Novak procedure (18), and the concentrations of oleic and eicosapentaenoic acid in plasma were calculated from the proportions in plasma FFA obtained by gas chromatography. The respective specific radioactivities could then be calculated. An aliquot of the infusate was also extracted, together with unlabeled carrier FFA, to determine the infusion rates of the two labeled FFA. The calculations were by the formula: flux of oleic acid or eicosapentaenoic acid $(\mu \mathrm{M} / \mathrm{min})=$ rate of infusion of FFA radioactivity $(\mathrm{dpm} / \mathrm{min}) /$ specific radioactivity of FFA $(\mathrm{dpm} / \mu \mathrm{M})$ (reference 14$)$.

Gas chromatography of total plasma fatty acids in subjects $1-6$ and of plasma FFA in subjects 8-11 was performed after methylating the fatty acids, by use of a 12-m capillary column packed with dimethyl silicone fluid-carbowax, $20 \mathrm{M}$, in a temperature programmed chromatograph (Hewlett Packard, Co., Scientific Instruments Div., Palo Alto, CA). Calibration and identification of fatty acid esters were carried out with known standards and areas were derived by integration.

The cholesterol and triglyceride concentrations were measured by automated enzymic methods in whole plasma and in the ultracentrifugally isolated lipoproteins and in high density lipoprotein (HDL) obtained after precipitation of other lipoproteins with heparin-manganese chloride
(19). Apoprotein $A_{1}$ concentrations in plasma were measured by electroimmunoassay (20).

\section{Results}

The major effect of dietary fish oil on plasma lipids and lipoproteins was on the triglyceride content of VLDL, which was reduced strikingly (Table III). The plasma triglyceride concentration in the most hyperlipidemic subject (subject 5) was lowered to normal. In the five normolipidemic subjects (1-4 and 7) the fish oil diet was also highly effective, and in subject 2 VLDL triglyceride was almost unmeasurable.

Since the cholesterol and apoprotein B concentrations in VLDL also fell, the fish oil diet reduced the number of circulating particles and not merely the triglyceride content. IDL particles were similarly affected. On the other hand, LDL concentrations tended to rise with higher LDL cholesterol and LDL apoprotein $B$ levels in several subjects. HDL particle number (apoprotein $A_{1}$ levels) and HDL cholesterol concentrations were generally lower with fish oil.

Table IV shows the degree of enrichment of plasma lipid with the specific PUFA of fish oil. Only the major fatty acids are shown. The major changes from the safflower oil to the fish oil diet comprised substantial reductions in oleate (18:1) and linoleate (18:2) and very large increments in eicosapentaenoate (20:5) and docosahexaenoate (22:6).

Table III. Cholesterol and Triglyceride Concentrations in Plasma and Plasma Lipoproteins and Apoprotein B and AI Concentrations at the End of Each of the Two Diets (mg/dl)

\begin{tabular}{|c|c|c|c|c|c|c|c|c|c|c|c|c|c|c|c|}
\hline \multirow{2}{*}{$\begin{array}{l}\text { Sub- } \\
\text { ject }\end{array}$} & \multirow[b]{2}{*}{ Study } & \multicolumn{2}{|c|}{ Whole plasma } & \multicolumn{3}{|c|}{ VLDL* } & \multicolumn{3}{|c|}{ IDL* } & \multicolumn{3}{|l|}{ LDL } & \multicolumn{2}{|c|}{ HDL } & \multirow{2}{*}{$\begin{array}{l}\text { Plasma } \\
\text { apoprotein AI }\end{array}$} \\
\hline & & $\mathrm{CH}$ & TG & $\mathrm{CH}$ & TG & B & $\mathrm{CH}$ & TG & B & $\mathrm{CH}$ & TG & B & $\mathrm{CH}$ & TG & \\
\hline \multirow[t]{2}{*}{1} & I & 108 & 94 & 14 & 43 & 6 & 11 & 15 & 5 & 35 & 15 & 21 & 48 & 21 & 100 \\
\hline & II & 94 & 42 & 6 & 18 & 2 & 8 & 2 & 2 & 41 & 8 & 22 & 39 & 14 & 85 \\
\hline \multirow[t]{2}{*}{2} & I & 138 & 100 & 16 & 44 & 9 & 12 & 24 & 4 & 70 & 20 & 35 & 40 & 14 & 97 \\
\hline & II & 110 & 18 & 5 & 2 & 1.2 & 7 & 3 & 3 & 69 & 2 & 51 & 29 & 11 & 69 \\
\hline \multirow[t]{2}{*}{3} & I & 176 & 44 & 9 & 18 & 4.4 & 5 & 3 & 8 & 114 & 10 & 69 & 48 & 13 & 124 \\
\hline & II & 159 & 31 & 7 & 10 & 0.6 & 4 & 1 & 3 & 100 & 10 & 68 & 48 & 10 & 115 \\
\hline \multirow[t]{2}{*}{4} & I & 134 & 85 & 10 & 60 & 7 & 4 & 2 & 3 & 78 & 11 & 48 & 42 & 12 & 141 \\
\hline & II & 130 & 48 & 4 & 14 & 2 & 3 & 5 & 2 & 92 & 12 & 63 & 31 & 17 & 127 \\
\hline \multirow[t]{2}{*}{5} & I & 264 & 822 & 141 & 627 & 60 & 30 & 98 & 6 & 62 & 66 & 51 & 31 & 31 & 118 \\
\hline & II & 182 & 156 & 30 & 58 & 22 & 27 & 42 & 4 & 101 & 18 & 76 & 24 & 38 & 82 \\
\hline \multirow[t]{2}{*}{6} & I & 325 & 518 & 50 & 350 & 16.4 & 34 & 88 & & 208 & 59 & & 33 & 21 & 123 \\
\hline & II & 299 & 207 & 33 & 111 & 10.9 & 20 & 45 & & 218 & 34 & & 28 & 17 & 113 \\
\hline \multirow[t]{2}{*}{7} & I & 112 & 44 & 7 & 19 & & & & & & & & & & \\
\hline & II & 94 & 12 & 1 & 3 & & & & & & & & & & \\
\hline
\end{tabular}

* VLDL, Sf 20-400; IDL, Sf 12-20; LDL, Sf 0-12. CH, cholesterol. TG, triglyceride. B, apoprotein B. I, safflower oil diet. II, fish oil diet. 
Table IV. Percentage Composition of Major Plasma Fatty Acids (>2\%) During the Two Dietary Periods in Six Subjects*

\begin{tabular}{|c|c|c|c|c|c|c|c|c|c|c|c|c|c|}
\hline \multirow[b]{2}{*}{ Fatty acid } & \multicolumn{2}{|l|}{1} & \multicolumn{2}{|l|}{2} & \multicolumn{2}{|l|}{3} & \multicolumn{2}{|l|}{4} & \multicolumn{2}{|l|}{5} & \multicolumn{2}{|l|}{6} & \multirow[b]{2}{*}{ Fish oil§ } \\
\hline & $\mathbf{S}$ & $\mathbf{F}$ & $\mathbf{S}$ & $F$ & $\mathbf{S}$ & $\mathbf{F}$ & $\mathbf{S}$ & $\mathbf{F}$ & $\mathbf{S}$ & $\mathbf{F}$ & $\mathbf{S}$ & $F$ & \\
\hline $14: 0$ & & 2 & & & & 2 & & 2 & 2 & 4 & 4 & 3 & 8 \\
\hline $16: 0$ & 27 & 26 & 25 & 22 & 25 & 24 & 26 & 24 & 27 & 34 & 27 & 22 & 19 \\
\hline $16: 1$ & 4 & 4 & 4 & 3 & 3 & 4 & 4 & 4 & 5 & 6 & 3 & 6 & 12 \\
\hline 18:0 & 6 & 6 & 6 & 8 & 5 & 5 & 5 & 6 & 6 & 6 & 6 & 5 & 3 \\
\hline 18:1 & 24 & 17 & 22 & 17 & 25 & 20 & 24 & 20 & 23 & 18 & 35 & 17 & 18 \\
\hline $18: 2$ & 25 & 15 & 29 & 13 & 25 & 18 & 26 & 18 & 25 & 11 & 18 & 12 & 4 \\
\hline $20: 4$ & 5 & 4 & 5 & 7 & 6 & 5 & 6 & 4 & 4 & 4 & 4 & 3 & $<1$ \\
\hline $20: 5$ & $<1$ & 4 & $<1$ & 12 & $<1$ & 7 & $<1$ & 7 & $<1$ & 7 & $<1$ & 10 & 17 \\
\hline 22:6 & $<1$ & 2 & $<1$ & 7 & $<1$ & 3 & $<1$ & 3 & $<1$ & 2 & $<1$ & 7 & 12 \\
\hline
\end{tabular}

S, safflower oil. F, fish oil (MaxEPA); LF, low fat. * Subject 7 was not studied. $¥ 14: 0$, myristate; 16:0, palmitate; 16:1, palmitoleate; 18:0, stearate; $18: 1$, oleate; $18: 2$, linoleate; $20: 4$, arachidonate; $20: 5$, eicosapentaenoate; $22: 6$, docosahexaenoate. $\S$ The fish oil contained other fatty acids that comprised $>2 \%$ of total but were not reflected in the plasma fatty acids.

$V L D L$ apoprotein B kinetics. The transport of VLDL apoprotein B was markedly reduced with dietary fish oil in every subject, falling by as much as $80 \%$ in subject 2 , in whom plasma triglyceride also fell the most (Table V). Although the reduction in pool size was largely explicable in terms of reduced transport (presumably reflecting reduced secretion of VLDL), the irreversible fractional removal rate tended to fall in the two hyperlipidemic subjects ( 5 and 6 ), in contrast with the rise in the four normolipidemic men (subjects 1-4).

Dietary fish oil altered the relationship between the apo-

Table V. Transport of VLDL Apoprotein B at the End of Each of the Two Diets

\begin{tabular}{llrrr}
\hline Subject & Diet & \multicolumn{1}{c}{ Pool $^{*}$} & FCR & Flux \\
\hline \multirow{3}{*}{1} & & \multicolumn{1}{c}{$m g$} & $d^{-1}$ & $m g / d$ \\
& S & 148 & 3.15 & 468 \\
2 & F & 49 & 5.82 & 285 \\
& S & 300 & 5.30 & 1588 \\
3 & F & 40 & 6.37 & 254 \\
& S & 133 & 6.24 & 829 \\
4 & F & 18 & 9.60 & 173 \\
& S & 202 & 7.08 & 1430 \\
5 & F & 54 & 11.28 & 609 \\
& S & 2160 & 2.08 & 4492 \\
6 & F & 762 & 1.95 & 1486 \\
& S & 1139 & 3.18 & 3622 \\
& F & 515 & 2.87 & 1478 \\
\hline
\end{tabular}

S, safflower oil. F, fish oil.

* Data for kinetics in pool A, the rapidly equilibrating pool. protein B specific radioactivity curves for IDL and LDL. Whereas in each of the six safflower oil studies the respective curves for IDL and LDL showed precursor-product relationships, this was not the case during the fish oil study in subject 2 , in whom VLDL lipids were highly depleted. As shown in Fig. 1, the LDL apoprotein B specific radioactivity curve peaked well before it crossed the IDL curve, suggesting substantial derivation of LDL from a source other than IDL. Similar findings, though of lesser magnitude, were also observed in subject 5 .

$V L D L$ triglyceride kinetics. The data are shown in Table VI. In every subject, the substantial fall in VLDL triglyceride concentration was accompanied by a striking reduction in flux. As with the apoprotein B studies, the changes (reductions) in flux were far greater than the changes (rises) in fractional removal rate, confirming that diminished production was the major cause for the hypotriglyceridemic effect of the fish oil.

Free fatty acid flux. The plasma total FFA concentrations were in the normal range $(21,22)$, contrasting with the very low plasma triglyceride levels (Table VII). The total flux of plasma FFA can also be estimated on the assumption that oleic acid represents average FFA transport. Since the mean flux of oleic acid in the four subjects was $155 \mu \mathrm{M} / \mathrm{min}$ and constituted about one quarter of the plasma FFA mass, the approximate total FFA flux was on the order of $620 \mu \mathrm{M} / \mathrm{min}$ which is in the reported normal range $(21,22)$. The flux of eicosapentaenoic acid was high relative to its concentration; whereas the concentration of eicosapentaenoic acid was, on the average, $8 \%$ of that of oleic acid, its flux averaged $19 \%$ of that of oleate.

\section{Discussion}

Effects on lipid and lipoprotein concentrations. This study has confirmed the substantial triglyceride-lowering effect of $\omega-3$ PUFA (2-4). The magnitude appeared to be dose related, being greatest in subjects who received $29 \%$ of energy needs from the 

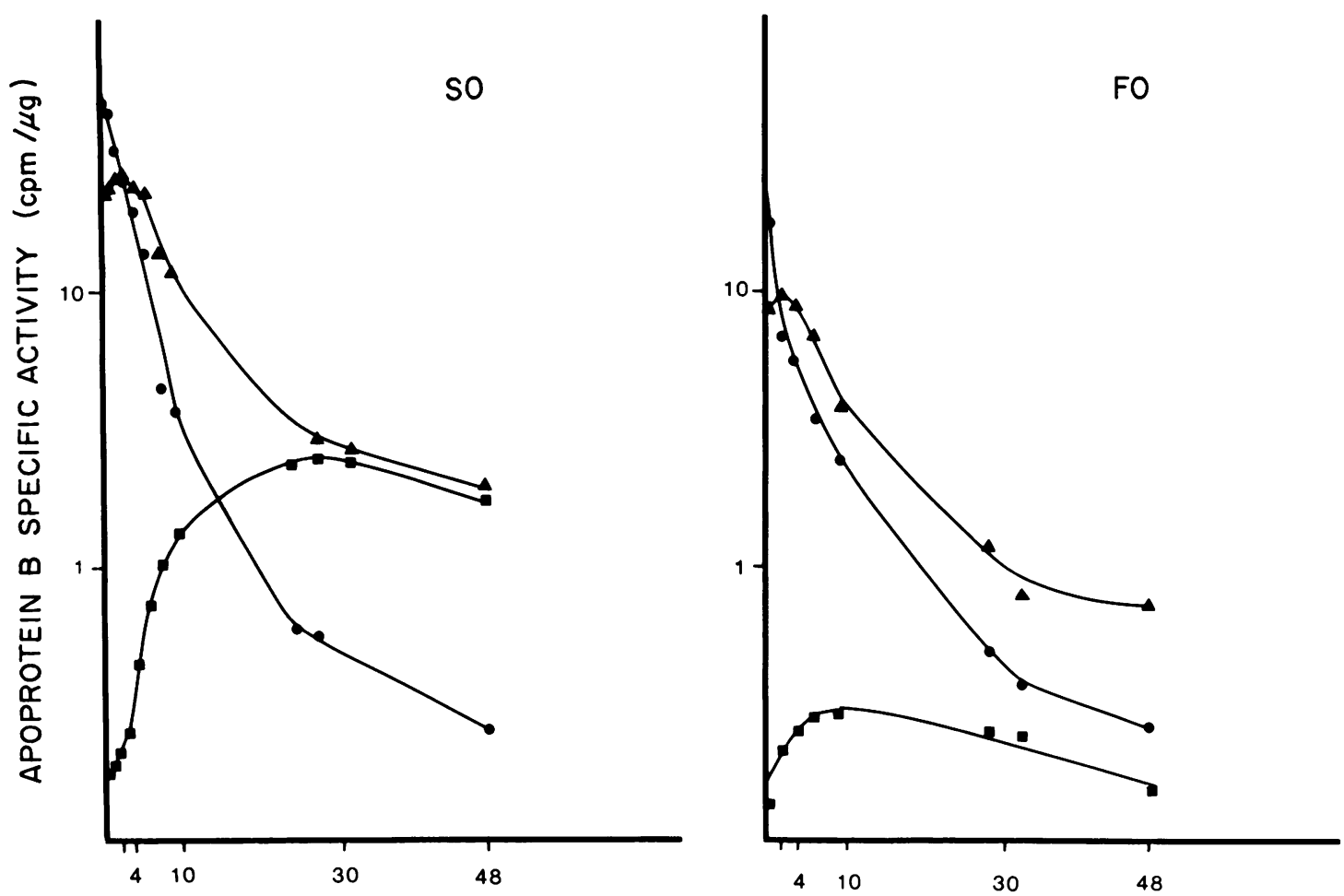

Figure 1. Specific radioactivity-time curve of apoprotein B in VLDL, IDL, and LDL during the safflower oil (SO) diet (left) and fish oil

(FO) diet (right) for subject 2. Time is in hours. ๑, VLDL., IDL. $\square$, LDL.

fish oil. Whereas total cholesterol levels in plasma were also reduced, this reduction was smaller and reflected the various changes in lipoproteins. Two points may be worth noting. First, the normolipidemic subjects showed habitual plasma cholesterol

Table VI. VLDL Concentrations, Fractional Removal Rates, and Fluxes of Triglyceride (TG)

\begin{tabular}{lllll}
\hline Subject & Diet & VLDL TG & $\begin{array}{l}\text { Irreversible } \\
\text { fractional } \\
\text { removal }\end{array}$ & Flux \\
\hline \multirow{3}{*}{2} & & $m g / d l$ & $h^{-1}$ & $m g / k g$ per $h$ \\
& S & 44 & 0.34 & 5.91 \\
4 & F & $<5$ & 1.24 & 0.98 \\
& S & 60 & 0.89 & 19.48 \\
5 & F & 14 & 0.56 & 2.65 \\
& S & 627 & 0.13 & 33.27 \\
6 & F & 58 & 0.23 & 5.08 \\
& S & 350 & 0.13 & 14.78 \\
7 & F & 111 & 0.22 & 8.09 \\
& S & 19 & 0.82 & 7.12 \\
& F & $<5$ & 0.98 & 1.34 \\
\hline
\end{tabular}

S, safflower oil. F, fish oil. levels (Table I) that were slightly below average for adult Australian men $(197 \mathrm{mg} / \mathrm{dl}$ for men aged 25-29 yr; unpublished data, 1980, National Heart Foundation of Australia Risk Factor Prevalence Survey. The survey average for the plasma triglyceride concentration was $98 \mathrm{mg} / \mathrm{dl}$.) Second, the large initial falls in plasma lipids during the first dietary period in subjects 1-4 and 7 reflected not only the large amount of safflower oil but also a reduced intake of total fat and cholesterol.

All lipoproteins were affected. The reductions in the lipids and in apoprotein B in VLDL and in IDL have been observed previously with linoleate-rich $(\omega-6)$ diets $(5,6,23-25)$, but the effects with $\omega-3$ PUFA are far greater. The cholesterol in HDL and apoprotein $A_{1}$ reductions have also been reported with $\omega-6$ PUFA (26). On the other hand, Sanders et al. (4) have reported a significant rise in HDL cholesterol when smaller amounts of $\omega-3$ PUFA were given as cod liver oil. However, the high cholesterol content of fish oils, if not matched carefully, may raise HDL cholesterol, which is known to increase when other sources of cholesterol are eaten $(27,28)$. The cholesterol content of our batch of fish oil was $364 \mathrm{mg} / 100 \mathrm{~g}$. The mechanism for the reduction in HDL, at least with $\omega-6$, has been attributed to diminished synthesis, since the fractional removal rate is unaltered (26).

The effect of $\omega-3$ PUFA on LDL was variable and clearly differed from that induced by $\omega-6$ PUFA, which generally lower LDL $(23,24)$. In fact, LDL cholesterol and apoprotein B rose 
Table VII. Plasma FFA Concentration, and the Fluxes of Eicosapentaenoic and Oleic Acids After 1 wk of Fish Oil*

\begin{tabular}{|c|c|c|c|c|c|c|c|}
\hline \multirow[b]{2}{*}{ Subject } & \multicolumn{2}{|l|}{ Plasma } & \multirow{2}{*}{$\begin{array}{l}\text { Plasma } \\
\text { FFA }\end{array}$} & \multicolumn{2}{|c|}{ FFA composition } & \multicolumn{2}{|l|}{ FFA flux } \\
\hline & Cholesterol & Triglyceride & & $18: 1$ & $20: 5$ & $18: 1$ & 20:5 \\
\hline & $m g / d l \ddagger$ & $m g / d l \neq$ & $\mu M / l i t e r$ & $\%$ & $\%$ & $\mu M / \min$ & $\mu M / \min$ \\
\hline 8 & 117 & 13 & 541 & 25 & 2.0 & 119 & 28 \\
\hline 9 & 120 & 32 & 430 & 25 & 2.8 & 100 & 32 \\
\hline 10 & 90 & 51 & 457 & 27 & 1.7 & 270 & 27 \\
\hline 11 & 120 & 44 & 461 & 28 & 1.9 & 128 & 13 \\
\hline
\end{tabular}

* These subjects received 20\% energy in the form of MaxEPA fish oil in order to raise eicosapentaenoic acid to measurable concentrations. ‡ Falls in triglyceride concentration in 1 wk of $34-69 \%$.

in several subjects. The data of Bronsgeest-Schoute et al. (29) also show increased LDL concentrations (density undefined) after a fish oil diet. On the other hand, Harris et al. (3) have observed reductions in LDL cholesterol and rises in HDL cholesterol with oils derived from salmon.

Effect on plasma fatty acids. A partial analysis of the fish oil used, as shown in Table IV, does not include three unusual fatty acids that accounted for $7 \%$ of the total but were present in trace amounts at most in the plasma (provisionally identified as 20:1 $\omega-9,18: 4 \omega-3$, and 22:1 $\omega-11)$. The major fatty acid of safflower oil is linoleic acid (67\% in the oil used in these studies). As expected, the long-chain $\omega-3$ PUFA of the fish oil were reflected in the plasmas at the expense of linoleic $(\omega-6)$ and oleic $(\omega-9)$ acids. This has been reported previously by BronsgeestSchoute et al. (29) and by Harris et al. (3).

$V L D L$ apoprotein $B$ and triglyceride kinetics. The striking reduction in daily flux or transport of apoprotein B in VLDL is clearly the major reason for the marked reduction in VLDL triglyceride and apoprotein B, being as much as $84 \%$ in subject 2.

The reduced VLDL apoprotein B pool size was accompanied by an increased irreversible fractional removal rate (FCR) in the four normolipidemic men (Table V). The most likely explanation is that the rise in FCR reflected merely the smaller pool rather than a primary effect on removal, since the FCR in the hypertriglyceridemic subjects was little altered. This was confirmed by the even more substantial falls in triglyceride formation in each of the five subjects. Again, changes in FCR were much less than in flux, indicating that the predominant effect of fish oil is on production.

Reduced formation has been put forward to explain the triglyceride lowering effect on $\omega-6$ PUFA. Nestel and Barter (5) and Chait et al. (6) have demonstrated a lower use of linoleic acid than of palmitic acid for triglyceride formation: there was a twofold greater fractional incorporation of palmitic than of linoleic acid into plasma triglyceride after the differences in the respective plasma free fatty acid fluxes were taken into account (5). Recently, Cortese et al. (30) have reported a reduced flux of VLDL apoprotein B with $\omega-6$ PUFA diets.

The conversion of VLDL to IDL, in terms of the respective apoprotein B specific radioactivity-time curves, appeared similar with both diets (Fig. 1). However, in two subjects the relationship between IDL and LDL curves was unusual with the fish oil diet. One conventional explanation for the peaking of the LDL apoprotein B specific radioactivity well before its intersection with the IDL curve is that there is substantial independent secretion of LDL-like particles; this was observed especially in subject 2. Similar findings have been reported with familial hypercholesterolemia (31) and this secretion occurs normally in the rat (32). This may reflect the paucity of secreted triglyceride, leading to the secretion of lipid-poor particles with the density of LDL.

FFA kinetics. The finding of normal values for plasma FFA transport indicates that the marked triglyceride lowering effect of fish oils is not due to a reduced availability of circulating fatty acid substrate. Although in these studies the fish oil was given for only $1 \mathrm{wk}$, this is enough time for plasma triglyceride to fall substantially. If anything, the contribution of eicosapentaenoic flux to total plasma FFA flux was high relative to that of oleic acid, although quantitatively it was nevertheless minor.

Whether this relatively high flux of eicosapentaenoic acid reflects a true metabolic characteristic of polyenoic acids is uncertain. Eicosapentaenoic acid may have been more readily available from adipose tissue stores, having become newly deposited there. On the other hand, we have shown previously that linoleic acid flux is high relative to that of palmitic acid (5). The metabolic fate of PUFA within the liver is not identical to that of more saturated fatty acids $(8,9)$. We have recently found significantly higher rates of fatty acid oxidation and ketogenesis and lower rates of lipogenesis in livers from MaxEPAfed than from safflower oil-fed rats (33). Further, less VLDL was secreted from the perfused livers of MaxEPA-fed rats (33). In studies with isolated hepatocytes, less $\left[{ }^{3} \mathrm{H}\right]$ glycerol was incorporated into hepatic triglyceride and less labeled triglyceride was secreted from hepatocytes of fish oil-fed than of safflower oil-fed rats (Wong, S., and P. J. Nestel, unpublished observation). These data in the rat support our findings in man of a primary reduction in triglyceride production in the liver, which may in part reflect diversion of polyenoic fatty acids to pathways of oxidation and ketogenesis. However, there may also be a suppression of VLDL secretion, and it is of interest that the hypertriglyceridemia induced with excess dietary carbohydrate 
can be significantly attenuated by enriching the dietary fat with fish oil (Harris, W., and W. E. Connor, unpublished observations).

\section{Acknowledgments}

We thank Patricia Nugent, Tim Billington, Annie Choy, and Helen Stratmann for expert technical and dietary help. MaxEPA was provided by R. P. Scherer Co., Melbourne.

This work was supported by the National Health and Medical Research Council of Australia.

\section{References}

1. Stansby, M. E. 1969. Nutritional properties of fish oils. World Rev. Nutr. Diet. 11:46-51.

2. Von Lossonczy, T. O., A. Ruiter, H. C. Bronsgeest-Schoute, C. M. Van Gent, and R. J. J. Hermus. 1978. The effect of a fish diet on serum lipids in healthy human subjects. Am. J. Clin. Nutr. 31:13401346.

2a. Harris, W. S., and W. E. Connor. 1980. The effects of salmon oil upon plasma lipids, lipoprotein and triglyceride clearance. Trans. Assoc. Am. Phys. 93:148-155.

3. Harris, W. S., W. E. Connor, and M. P. McMurry. 1983. The comparative reductions of the plasma lipids and lipoproteins by dietary polyunsaturated fats: salmon oil versus vegetable oils. Metabolism. 32:179-184.

4. Sanders, T. A. B., M. Vickers, and A. P. Haines. 1981. Effect on blood lipids and haemostasis of a supplement of cod-liver oil, rich in eicosapentaenoic and docosahexaenoic acids, in healthy young men. Clin. Sci. (Lond.). 61:317-324.

5. Nestel, P. J., and P. Barter. 1971. Metabolism of palmitic and linoleic acids in man: differences in turnover and conversion to glycerides. Clin. Sci. (Lond.). 40:345-350.

6. Chait, A., A. Onitiri, A. Nicoll, E. Rabaya, J. Davies, and B. Lewis. 1974. Reduction of serum triglyceride levels by polyunsaturated fat. Studies on the mode of action and on very low density lipoprotein composition. Atherosclerosis. 20:347-364.

7. Nestel, P. J., and P. J. Barter. 1973. Triglyceride clearance during diets rich in carbohydrate or fats. Am. J. Clin. Nutr. 26:241-245.

8. Davis, R. A., and J. R. Boogaerts. 1982. Intrahepatic assembly of very low density lipoproteins. Effect of fatty acids on triacylglycerol and apolipoprotein synthesis. J. Biol. Chem. 257:10908-10913.

9. Kohout, M., B. Kohoutova, and M. Heimberg. 1971. The regulation of hepatic triglyceride metabolism by free fatty acids. J. Biol. Chem. 246:5067-5074.

10. Havel, R. J., H. A. Eder, and J. H. Bragdon. 1955. The distribution and chemical composition of ultracentrifugally separated lipoproteins in human serum. J. Clin. Invest. 34:1345-1353.

11. McFarlane, A. S. 1958. Efficient trace labeling of proteins with iodine. Nature (Lond.). 182:53.

12. Holmquist, L., K. Carlson, and L. A. Carlson. 1978. Comparison between the use of isopropanol and tetramethylurea for solubilization and quantitation of human serum very low density apolipoproteins. Anal. Biochem. 88:457-460.

13. Lowry, O. H., N. J. Rosebrough, A. L. Farr, and R. J. Randall. 1951. Protein measurements with the Folin phenol reagent. J. Biol. Chem. 193:265-275.

14. Shipley, R. H., and R. E. Clark. 1972. Tracer Methods for In Vivo Kinetics. Academic Press Inc. New York.

15. Goodman, D. S., and R. P. Noble. 1968. The turnover of plasma cholesterol in man. J. Clin. Invest. 47:231-241.

16. Neri, B. P., and C. S. Frings. 1973. Improved method for determination of triglycerides in serum. Clin. Chem. 19:1201-1202.
17. Zech, L. A., S. M. Grundy, D. Steinberg, and M. Berman. 1979. Kinetic model for production and metabolism of very low density lipoprotein triglycerides. Evidence for a slow production pathway and results for normolipidemic subjects. J. Clin. Invest. 63:1262-1273.

18. Novak, M. 1965. Colorimetric ultramicro method for the determination of free fatty acids. J. Lipid Res. 6:431-433.

19. Warnick, R., and J. J. Alberts. 1978. A comprehensive evaluation of the heparin-manganese precipitation procedure for estimating high density lipoprotein cholesterol. J. Lipid Res. 19:65-76.

20. Curry, M. D., P. Alaupovic, and C. A. Suenram. 1976. Determination of apolipoprotein A and its constitutive A-I and A-II polypeptides by separate electroimmunoassays. Clin. Chem. 22:315-322.

21. Steinberg, D., P. J. Nestel, E. R. Buskirk, and R. H. Thompson. 1964. Calorigenic effect of norepinephrine correlated with plasma free fatty acid turnover and oxidation. J. Clin. Invest. 43:167-176.

22. Nestel, P. J. 1967. Relationships between FFA flux and TGFA flux in plasma before and during infusions of insulin. Metabolism. 16:1123-1132.

23. Ahrens, E. H., J. Hirsch, W. Insull, T. T. Tsaltas, R. Blomstrand, and M. L. Peterson. 1957. The influence of dietary fats on serum-lipid in man. Lancet. I:943-953.

24. Schonfeld, G., W. Patsch, L. L. Rudel, C. Nelson, M. Epstein, and R. E. Olson. 1982. Effects of dietary cholesterol and fatty acids on plasma lipoproteins. J. Clin. Invest. 69:1072-1080.

25. Vega, G. L., E. Groszek, R. Wolf, and S. M. Grundy. 1982. Influence on polyunsaturated fats on composition of plasma lipoproteins and apolipoproteins. J. Lipid Res. 23:811-822.

26. Shepherd, J., C. J. Packard, J. R. Patsch, A. M. Gotto, Jr., and O. D. Taunton. 1978. Effects of dietary polyunsaturated and saturated fat on the properties of high density lipoprotein and the metabolism of apolipoprotein A-I. J. Clin. Invest. 60:1582-1592.

27. Lin, D. S., and W. E. Connor. 1980. The long term effects of dietary cholesterol upon the plasma lipids, lipoproteins, cholesterol absorption, and the sterol balance in man: the demonstration of feedback inhibition of cholesterol biosynthesis and increased bile acid excretion. J. Lipid Res. 21:1042-1052.

28. Nestel, P., N. Tada, T. Billington, M. Huff, and N. Fidge. 1982. Changes in very low density lipoproteins with cholesterol loading in man. Metabolism. 31:398-405.

29. Bronsgeest-Schoute, H. C., C. M. van Gent, J. B. Luten, and A. Ruiter. 1981. The effect of various intakes of $\omega-3$ fatty acids on the blood lipid composition in healthy human subjects. Am. J. Clin. Nutr. 34:1752-1757.

30. Cortese, B., Y. Levy, E. D. Janus, P. R. Turner, S. N. Rao, N. E. Miller, and B. Lewis. 1983. Modes of action of lipid-lowering diets in man: studies of apolipoprotein B kinetics in relation to fat consumption and dietary fatty acid composition. Eur. J. Clin. Invest. 13:79-85.

31. Janus, E. D., A. Nicoll, R. Wooton, P. R. Turner, P. J. Magill, and B. Lewis. 1980. Quantitative studies of very low density lipoprotein: conversion to low density lipoprotein in normal controls and primary hyperlipidaemic states and the role of direct secretion of low density lipoprotein in heterozygous familial hypercholesterolaemia. Eur. J. Clin. Invest. 10:149-159.

32. Fidge, N. H., and P. Poulis. 1978. Metabolic heterogeneity in the formation of low density lipoprotein from very low density lipoprotein in the rat: evidence for the independent production of a low density lipoprotein subfraction. J. Lipid Res. 19:342-349.

33. Wong, S. H., P. J. Nestel, R. P. Trimble, G. B. Storer, R. J. Illman, and D. L. Topping. 1984. The adaptive effects of dietary fish and safflower oil on lipid and lipoprotein metabolism in perfused rat liver. Biochim. Biophys. Acta. 792:103-109. 